Andrews University

Digital Commons @ Andrews University

Faculty Publications

$1-1-1993$

\title{
Effects of Aerobic Training in Adolescents with Down Syndrome
}

A. Lynn Millar

Andrews University, Imillar@andrews.edu

Bo Fernhall

Andrews University

Lee N. Burkett

Andrews University

Follow this and additional works at: https://digitalcommons.andrews.edu/pubs

Part of the Physical Therapy Commons

\section{Recommended Citation}

Millar, A. Lynn; Fernhall, Bo; and Burkett, Lee N., "Effects of Aerobic Training in Adolescents with Down Syndrome" (1993). Faculty Publications. 2611.

https://digitalcommons.andrews.edu/pubs/2611

This Article is brought to you for free and open access by Digital Commons @ Andrews University. It has been accepted for inclusion in Faculty Publications by an authorized administrator of Digital Commons @ Andrews University. For more information, please contact repository@andrews.edu. 


\title{
Effects of aerobic training in adolescents with Down syndrome
}

\author{
A. LYNN MILLAR, BO FERNHALL, and LEE N. BURKETT \\ Department of Physical Therapy, \\ Andrews University, \\ Berrien Springs, $M I$ 49104-0420; and \\ Department of $H K L S$, \\ George Washington University \\ Washington, DC 20052
}

\begin{abstract}
MILLAR, A. L., B. FERNHALL, and L. N. BURKETT. Effects of aerobic training in adolescents with Down syndrome. Med. Sci. Sports Exerc., Vol. 25, No. 2, pp. 270-274, 1993. The purpose of this study was to evaluate the effects that aerobic training has on adolescents and young adults with Down syndrome. Fourteen individuals with Down syndrome (mean age $=17.7 \mathrm{yr}$ ) participated in a 10 -wk walking/jogging exercise training study. A pre- and post-training walking treadmill test was performed to determine the following parameters: peak oxygen uptake ( $\mathrm{VO}_{2}$, absolute and relative), minute ventilation $\left(\dot{\mathrm{V}}_{\mathrm{E}}, 1 \cdot \mathrm{min}^{-1}\right)$, heart rate $\left.\mathrm{HR}, \mathrm{b} \cdot \mathrm{min}^{-1}\right)$, RER $\left(\dot{\mathrm{V} C \mathrm{C}_{2}}\right.$ / $\dot{\mathrm{V}} \mathrm{O}_{2}$ ), and time and grade to exhaustion. Following the pre-training evaluations, subjects were assigned to a control group $(N=4)$ or an exercise group $(N=10)$. The exercise group underwent a 10-wk walk/ jog training program at a frequency of 3 times per week, for a duration of $30 \mathrm{~min}$, and at an intensity, of approximately $65-75 \%$ peak HR. Following training, both control and experimental groups showed no changes in peak $\mathrm{VO}_{2}$ (absolute and relative), $\dot{V E}$, HR, and RER. The exercise group, however, did demonstrate a significant improvement in peak exercise time (and grade). Although the training program did not produce improvements in aerobic capacity, it did produce gains in walking capacity. It was concluded that the adolescents and young adults may not be able to improve their aerobic capacity when performing a walk/jog training program.
\end{abstract}

EXERCISE TRAINING, CARDIOVASCULAR FITNESS, DOWN SYNDROME

$\mathrm{S}$ tudies of individuals with mental retardation found peak $\dot{\mathrm{VO}}_{2}$ values substantially lower than those reported for individuals without mental retardation of similar gender and age, even when objective criteria for $\dot{\mathrm{VO}}_{2 \max }$ determination were used $(6,11,13,24,25,27)$. It is not known why the individual with mental retardation has low peak $\dot{\mathrm{VO}}_{2}$ values, but several authors hypothesized that a combination of inactive lifestyles and low maximal heart rates may be

$0195-9131 / 93 / 2502-0270 \$ 3.00 / 0$

MEDICINE AND SCIENCE IN SPORTS AND EXERCISE

Copyright (c) 1993 by the Americun College of Sports Medicine

Submitted for publication January 1992.

Accepted for publication May 1992. responsible $(11,13,24,27)$. In addition, when individuals with Down syndrome were compared to their peers with mental retardation but without Down syndrome, the group with Down syndrome displayed inferior cardiovascular fitness $(19,23,25)$.

Several training studies with individuals with mental retardation (without DS) have shown that this population can show appreciable gains in cardiovascular fitness based on performance tests $(5,7,12,18,27,29)$. However, it has not yet been demonstrated that individuals with Down syndrome have the same capacity for improvement in cardiovascular capacity. Andrew et al. (2) found no significant changes in peak $\mathrm{VO}_{2}$ of individuals with mental retardation following $12 \mathrm{wk}$ of training, though they did find significant improvements in minute ventilation, heart rate, and exercise duration. However, Schurrer et al. (27) did find significant improvements in peak $\mathrm{VO}_{2}$ of five adults with mental retardation following $23 \mathrm{wk}$ of training, but no control group was included. Kasch and Zasueta (17) showed similar results with six children with mental retardation, although their study may be influenced by sampling bias as they tested only six of their 41 subjects for peak $\dot{\mathrm{V}} \mathrm{O}_{2}$. Pitetti and Tan (24) recently found a $16 \%$ increase in peak $\mathrm{VO}_{2}$ after a 16 -wk training program with individuals with mental retardation. Although they did not include a control group, 6- to 7-month follow-up showed that peak $\dot{\mathrm{VO}}_{2}$ was back to original levels.

It has been suggested that individuals with Down syndrome may respond differently to training because their response to maximal exercise differs from both persons with and without mental retardation, but without Down syndrome $(21,22,25)$. Furthermore, exercise training may have important implications for this population regarding health, longevity, and productivity $(14,24)$. However, to date there are no training studies involving only individuals with Down syndrome. The purpose of this study, therefore, was to determine 
whether individuals with Down syndrome could improve their cardiovascular fitness following a 10-wk walk/jog training program.

\section{METHODOLOGY}

Subjects. Fourteen adolescent volunteers with Down syndrome (11 males, 3 females) were recruited from two county schools. All subjects lived at home and were bused to school daily. IQ scores could not be released for the subjects, but were estimated to range between 30 and 70 , based upon their classification as trainable or educable mentally retarded. Descriptive statistics are presented in Table 1. All subjects were healthy and had medical clearance from either a personal physician, school, or vocational training center health staff. No subjects with ambulatory, musculoskeletal, severe visual, or auditory problems were included in the study. All subject and their parents or legal guardians gave informed, voluntary consent prior to participating in this study.

Procedures. The subjects were familiarized with the laboratory and taught to walk comfortably on a motorized treadmill prior to testing following a scheme previously described (11). A modified Balke protocol was used to elicit maximal oxygen consumption (4). Test speed was $3 \mathrm{mph}$ and the grade increased $21 / 2 \%$ every minute until the subject was exhausted. Reliability and validity of maximal treadmill testing with this population has been previously established $(11,15)$.

Open circuit spirometry was used to collect expired gases during the treadmill test. Air was collected in Douglas bags every minute with the last $3 \mathrm{~min}$ of each test being analyzed. Oxygen and carbon dioxide concentration were analyzed using an Applied ElectroChemistry analyzer (model S-3A) and a Beckman LB2 analyzer, respectively. Analyzers were calibrated prior to each test following manufacturer's recommendations and two known calibration gases. Expired gas volume was measured with a Parkinson-Cowan flowmeter, and ECGs were monitored continuously with a strip taken the final $15 \mathrm{~s}$ of each minute using a Narco-Biosystems physiograph. Heart rates were calculated from the ECGs and oxygen consumption values were calculated for each minute, with the last full minute of collection representing maximum.

Following the first test, subjects were randomly divided into two groups; 10 in the experimental group (group 1) and four in the control group (group 2).

TABLE 1. Subject descriptive characteristics

\begin{tabular}{llll}
\hline & Weight (kg) & Height (cm) & Age (yr) \\
\hline Experimental $(N=9)$ & $66.5 \pm 12.5$ & $153.7 \pm 7.1$ & $18.4 \pm 2.9$ \\
Control $(N=4)$ & $58.4 \pm 25.3$ & $150.0 \pm 15.8$ & $17.0 \pm 2.8$ \\
\hline
\end{tabular}

Mean $\pm \mathrm{SD}$.
Group 2 did not participate in any regular physical training. The groups were matched on a $2: 1$ ratio for gender and oxygen consumption.

Training intervention consisted of $10 \mathrm{~min}$ of warmup activities, $30 \mathrm{~min}$ of continuous brisk walking and jogging, followed by a 5- to 10-min cool-down, three times per week, for $10 \mathrm{wk}$. Target heart rates were calculated at $65-75 \%$ of maximal heart rate reached during the treadmill test results. Subjects' training heart rates were monitored at random during the training sessions using palpation with the subject slowing to a walk during the heart rate check. Each subject was checked on an intermittent basis for compliance with target heart rate, usually one to two times per session. Retesting was done after $10 \mathrm{wk}$ following the procedures described for pretraining.

Repeated measures ANOVAs were used to evaluate the effect of the training program on maximal HR, $b$. $\mathrm{min}^{-1}, \dot{\mathrm{V}}_{\mathrm{E}} \mathrm{l} \cdot \mathrm{min}^{-1}$, BTPS, $\mathrm{VO}_{2} \mathrm{ml} \cdot \mathrm{kg} \cdot{ }^{-1} \mathrm{~min}^{-1}, \mathrm{STPD}$, RER, and treadmill performance. Tests for statistical significance were made at the $\leq 0.05$ level of probability.

\section{RESULTS}

Pre and post oxygen consumption data including $\dot{V}_{\mathrm{E}}$ $1 \cdot \mathrm{min}^{-1}, \mathrm{VO}_{2} \mathrm{ml} \cdot \mathrm{kg} \cdot{ }^{-1} \mathrm{~min}^{-1}, \mathrm{HR}$, and RER are presented in Table 2. The groups had similar pretraining oxygen consumption values (Table 2). Post-training values did not differ significantly from pretraining for any of the metabolic measures. Maximum HR, though not significantly different, was slightly higher for group 1 than for group 2 prior to training. A comparison of the treadmill test grades shows a significant improvement for the training group, as illustrated in Figure 1, with a pretraining average test time of $8.84(8 \mathrm{~min}$ and $50 \mathrm{~s}) \mathrm{min}$ and a post-training average test time of 9.60 $(9 \mathrm{~min}$ and $56 \mathrm{~s}$ ) $\mathrm{min}$.

\section{DISCUSSION}

The oxygen consumption values for these subjects were low but similar to values for subjects with MR found by Burkett and Ewing $\left(30.68 \mathrm{ml} \cdot \mathrm{kg} \cdot{ }^{-1} \mathrm{~min}^{-1}\right.$.) (6), Schurrer et al. $\left(25.3 \mathrm{ml} \cdot \mathrm{kg} \cdot{ }^{-1} \mathrm{~min}^{-1}\right)(27)$, and

TABLE 2. Oxygen consumption data

\begin{tabular}{|c|c|c|c|c|}
\hline & $\dot{V}_{E}\left(1 \cdot m^{-1} n^{-1}\right)$ & 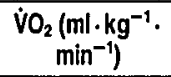 & $\begin{array}{c}\text { Heart Rate (b. } \\
\left.\text { min }^{-1}\right)\end{array}$ & RER \\
\hline \multicolumn{5}{|l|}{ Group 1} \\
\hline $\begin{array}{c}\text { Pre } \\
\text { Post } \\
\text { Group 2 }\end{array}$ & $\begin{array}{l}52.24 \pm 12.22 \\
49.82 \pm 13.24\end{array}$ & $\begin{array}{l}26.95 \pm 7.92 \\
25.56 \pm 7.82\end{array}$ & $\begin{array}{l}172.80 \pm 15.10 \\
167.20 \pm 11.80\end{array}$ & $\begin{array}{l}1.01 \pm 0.05 \\
1.03 \pm 0.11\end{array}$ \\
\hline $\begin{array}{l}\text { Pre } \\
\text { Post }\end{array}$ & $\begin{array}{l}48.50 \pm 7.19 \\
48.82 \pm 13.24\end{array}$ & $\begin{array}{l}26.22 \pm 5.85 \\
26.24 \pm 5.15\end{array}$ & $\begin{array}{l}165.80 \pm 14.00 \\
169.80 \pm 12.90\end{array}$ & $\begin{array}{l}1.05 \pm 0.05 \\
1.04 \pm 0.05\end{array}$ \\
\hline
\end{tabular}

Mean \pm SD. 


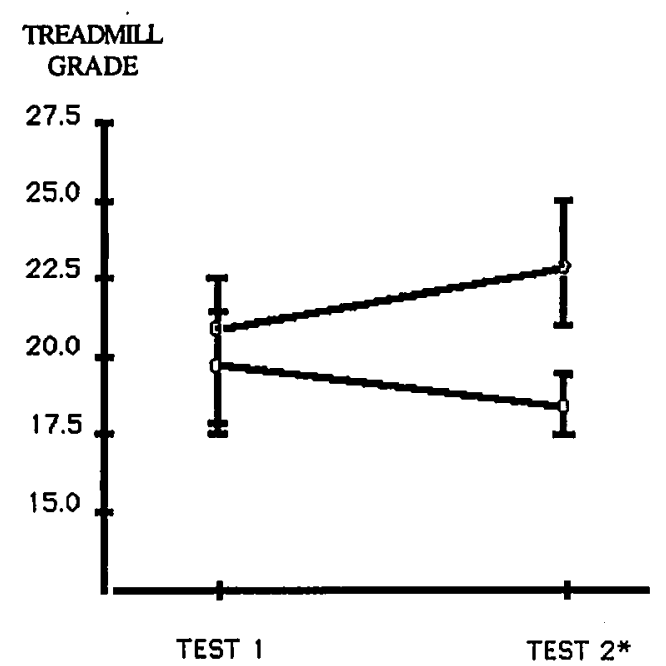

Figure 1-Mean treadmill test time as represented by \% grade: in experimental group $(\odot)$ and control group $(O)$ before and after a 10 wk walking/jogging program. Values are means \pm SD. ${ }^{*} P<0.00089$.

Fernhall and Tymeson $\left(26.31 \mathrm{ml} \cdot \mathrm{kg} \cdot{ }^{-1} \min ^{-1}\right)(13)$. However, the values in this study were slightly higher than those reported by Pitetti et al. (21) for a group of 25 -yr-old individuals with Down syndrome $(23.0 \mathrm{ml}$. $\left.\mathrm{kg} \cdot{ }^{-1} \mathrm{~min}^{-1}\right)$. In a recent study comparing individuals with Down syndrome to individuals with mental retardation but without Down syndrome, Pitetti et al. (25) found a mean $\dot{\mathrm{VO}}_{2}$ of 24.6 and $35.6 \mathrm{ml} \cdot \mathrm{kg} \cdot{ }^{-1} \mathrm{~min}^{-1}$, respectively, thus substantiating the difference in cardiovascular capacities between individuals with and without Down syndrome. These low values for cardiovascular fitness have also been shown using field tests to estimate peak $\mathrm{VO}_{2}(5,14)$. Therefore, it is likely that our subjects were a representative group of individuals with mild and moderate mental retardation.

Although we did not find a significant improvement in peak $\mathrm{VO}_{2}$, our data correspond well with those of Andrew et al. (2), who reported significant improvements in minute ventilation, exercise heart rate, and exercise duration, but not in peak $\mathrm{VO}_{2}$, for 10 adults who were classified as educably retarded. Conversely, Schurrer et al. (27) trained five adults with mental retardation for $23 \mathrm{wk}, 3 \mathrm{~d} \cdot \mathrm{wk}^{-1}$, using jogging, and found a $43 \%$ increase in peak $\mathrm{VO}_{2}$ following training. It is important to note that they used a much longer training period and also found a significant reduction in body weight. However, even when measured in 1 . $\min ^{-1}$, the increase in peak $\mathrm{VO}_{2}$ was $36 \%$. This is a much greater increase than one would expect from a group of subjects without mental retardation, especially with a mean training distance of only $9 \mathrm{~km} \cdot \mathrm{wk}^{-1}$. Pitetti and Tan (24) trained 12 adults with mental retardation for $16 \mathrm{wk}$ and showed a more moderate increase of $16 \%$ in peak $\mathrm{VO}_{2}$, which reverted back to pretraining levels after a 6- to 7-month follow-up. They suggested that it is imperative to closely monitor exercise training intensity, if results are to be properly interpreted, in studies that show significant improvements in subjects with mental retardation. We did, however, monitor training intensity and the compliance rate was surprisingly good (85\%). Yet, our subjects failed to improve peak $\dot{\mathrm{VO}}_{2}$, even though we followed a training regime that should have produced improvements $(1,3,16)$. It is possible that the average compliance rate is an overestimation of individual compliance due to the random monitoring and limited number of heart rates taken during each session, however, it seems logical that there should still have been some improvement in peak $\mathrm{VO}_{2}$ with such a low starting fitness level.

Considering that the subjects in Pitetti and Tan's (24) study were adults with mental retardation but without Down syndrome, and that Schurrer et al. (27) did not identify their subjects as having Down syndrome, it is possible that individuals with Down syndrome do not respond to training in a conventional manner. This would be consistent with previous studies that showed adults with Down syndrome to be physiologically limited compared to their peers without Down syndrome $(22,25)$. The possibility of a decreased response to training, as suggested by Nordgren (18) seems plausible considering that one would expect significant gains in peak $\dot{\mathrm{VO}}_{2}$ following the training program used in this study with individuals without mental retardation (4). The reason for a reduced training response is difficult to isolate, but may be related to the reduction in sympathetic response shown by Eberhard et al. (10) in subjects with Down syndrome. This could explain the lower maximal heart rates in our study and that of Pitetti et al. (25) and may also reduce the response to training.

The apparent lack of training results must be examined carefully. Performance based indices of peak $\dot{\mathrm{VO}}_{2}$ can be improved without actual gains in peak $\mathrm{VO}_{2}$ $(8 ; 9)$. Although no statistically significant changes were found in peak $\mathrm{VO}_{2}$, it might be argued that a training effect was produced, as evidenced by the increased treadmill test time following training. The subjects reached a greater treadmill grade (directly related to test time) with a lower heart rate and $\dot{\mathrm{VO}}_{2}$. This combination of results suggests a trend toward lower oxygen consumption values at a higher workload for the experimental group; no similar trend was noted for the control group. These data also correspond to other studies of persons with mental retardation that found increased cardiovascular fitness with training when using tests that predict peak $\mathrm{VO}_{2}$ to measure the gains. Several other factors such as improved endurance, test familiarity, better pacing, reduced anxiety, etc., may explain why gains in exercise endurance can occur without gains in peak $\mathrm{VO}_{2}(12,13)$. Furthermore, stud- 
ies of runners without mental retardation substantiate these findings, showing that running performance can increase with training without a change in peak $\dot{\mathrm{VO}}_{2}$ (9). It has been postulated that this may be due to improvements in running economy (8). Consequently, it may be important to evaluate training gains from variables other than peak $\mathrm{VO}_{2}$ which may be especially important for individuals with mental retardation.

It is important to realize that individuals with mental retardation are often less motivated and typically do not exercise at intensities above comfortable levels (26). Throughout the training sessions, constant encouragement and exhortation were necessary to keep the subjects going, even when only walking. If left to themselves, they would stop immediately, especially if there were diversions of any type. Although motivation was not as difficult after a few weeks into the programs, it still remained a small problem. Consequently, the training intensity was variable and the heart rates were usually at the low end of the prescribed target heart rates. However, considering the high overall compliance with the prescribed training intensity, at least a small improvement in peak $\dot{V O}_{2}$ was expected. Yet, the high compliance suggests that motivational problems did not significantly influence our results.

\section{REFERENCES}

1. American College of Sports Medicine. Guidelines for Exercise Testing and Prescription for Exercise, 4th ed. Philadelphia: Lea \& Febiger, 1990.

2. ANDREW, G. M., J. G. Reid, S. BeCK, and W. MCDonald. Training of the developmentally handicapped young adult. $C a n$. J. Appl. Sport Sci. 4:289-293, 1979.

3. ASTRAND, P. O. and K. RoDAhL. Textbook of Work Physiology, 2nd ed. New York: McGraw-Hill, 1977, pp. 358-359.

4. BALKE, B. and R. WARE. An experimental study of physical fitness of Air Force personnel. U.S. Armed Forces Med. J. 10:675-688, 1959.

5. BEASLEY, C. R. Effects of a jogging program on cardiovascular fitness and work performance of mentally retarded adults. $\mathrm{Am}$. J. Ment. Defic. 86:609-613, 1982.

6. BURKLTT, L. N. and H. EwING. Max $\mathrm{VO}_{2}$ uptake on five trainable mentally retarded high school students (Abstract). Abstracts of Research Papers, Washington, DC: AAHPERD, 1984.

7. CAMPBELl, J. Improving physical fitness of retarded boys. Ment. Retard. 12:31-35, 1974

8. Conley, D. L. and G. S. Krahenbuhl. Running economy and distance performance of highly trained athletes. Med. Sci. Sports Exerc. 12:357-360, 1986.

9. DANIELS, J. T. Changes in $\dot{V}_{2 \max }$ and running performance with training. Am. J. Appl. Physiol. 39:249-254, 1978.

10. Eberhard, Y., J. ETERradossi, and A. Therminarias. Biochemical changes and catecholamine responses in down's syndrome adolescents in relation to incremental maximal exercise. J. Ment. Defic. Res. 35:140-146, 1991.

11. Fernhall, B. and G. Tymeson. Graded exercise testing of mentally retarded adults: A study of feasibility. Arch. Phys. Med. Rehabil. 68:363-365, 1987.

12. FERnhAlL, B. and G. TYMESON. Validation of cardiovascular fitness field tests for adults with mental retardation. Adapt. Phys. Act. Quart. 5:49-59, 1988.

13. Fernhill, B., G. Tymeson, and G. Webster. Cardiovascular
The low peak $\mathrm{VO}_{2}$ values of persons with mental retardation present inherent clinical problems. It is expected that peak $\dot{\mathrm{VO}}_{2}$ will further decrease with aging (3), which could render the persons incapable of performing even light activities of daily living (20). Furthermore, this population will be at increased risk for future cardiovascular events (28). Interestingly, a "normal" training program, like the one employed herein, does not appear to increase peak $\mathrm{VO}_{2}$ in subjects with Down syndrome. This may mean that other forms of training are needed or that other measurements should be used to evaluate the effect of exercise training. Our results suggest that improvements that would be clinically important, such as gains in endurance and physical work capacity, can be attained without increases in peak $\dot{\mathrm{V}}_{2}$. Further investigations regarding potential improvements in economy of performance are indicated. Whether exercise programs will decrease the risk of future cardiovascular events of this population remains to be investigated.

Present address for Lee N. Burkett, Ph.D., is Dept. of Exercise Science, Arizona State University, Tempe, AZ 85287.

Address for correspondence: A. Lynn Millar, Ph.D., Physical Therapy Department, Andrews University, Berrien Springs, MI 491040420.

fitness of mentally retarded individuals. Adapt. Phys. Act. Quart. $51: 12-28,1988$

14. Fernhali, B., G. Tymeson, A. L. Millar, and L. Burkett. Cardiovascular fitness testing and fitness levels of adolescents and adults with mental retardation including Down syndrome. Educ. Train. Ment. Retard. (June):133-138, 1989.

15. Fernhall, B., G. Tymeson, A. L. Millar L., and L. Burkett. Maximal exercise testing of mentally retarded adolescents and adults: reliability study. Arch. Phys. Med. Rehabil. 71:1065-1068, 1990.

16. ISSEKUTZ, B. JR, N. C. BIRKHEAD, and K. RoDAHL. Use of respiratory quotients in assessment of aerobic work capacity. $J$. Appl. Physiol. 17:47-51, 1962.

17. KASCH, F. W. and S. A. Zasueta. Physical capacities of mentally retarded children. Acta Paediatr. Scand Suppl. 217:114-118, 1971.

18. NORDGREN, B. Physical capacity and training in a group of young adult mentally retarded persons. Acta Paediatr. Scand. 271(Suppl.):119-121, 1971.

19. PitetTI, K. H. and K. D. Campbell. Mentally retarded individuals-a population at Risk? Med. Sci. Sports Exerc. 23:586-593, 1991.

20. Pitetri, K. H., J. E. Fernandez, D. C. Pizzarro, N. B. Stubbs, and J. A. STAFFord. The cardiovascular fitness of non-Down's syndrome, moderately retarded individuals as an additional index for job placement. In: Trend in Ergonomics and Human Factors, Vol. V. Proceedings of the Annual International Industrial Ergonomics and Safety Conference, 1988, pp. 999-1005.

21. Pitetti, K. H., J. E. Fernadez, J. A. Stafford, and N. B. STuBBs. Evaluating the cardiovascular fitness of Down syndrome individuals. In: Trends in Ergonomics/Human Factors V, F. Aghazadeh (Ed.). North-Holland: Elsevier Science Publishers, 1988, pp. 941-947.

22. Pitetti, K. H., J. A. Jackson, M. J. Mays, J. E. Fernandez, and N. B. StuBss. Comparison of the physiological profiles on 
Down and non-Down syndrome mentally retarded individuals. Human Factors Association of Canada, 2 I st Annual Conference Proceedings, 1988, pp. 45-48.

23. PitetTI, K. H. and D. M. TAN. Cardiorespiratory responses of mentally retarded adults to air-brake ergometry and treadmill exercise. Arch. Phys. Med. Re/habil. 71:318-321, 1990.

24. PITETTI, K. H. and D. M. TAN. The effects of a minimally supervised training program on the cardiovascular fitness of mentally retarded adults. Med. Sci. Sports Exerc. 23:594-601, 1991.

25. Pitetti, K. H., M. Climstein, K. D. Campbell, P. J. Barrett, and J. A. JACKSON. The cardiovascular capacities of adults with Down syndrome: a comparative study. Med. Sci. Sports Exerc. 24:13-19, 1992.
26. Porter, R. B., J. L. Collins, and M. R. MCIVER. A comparative investigation of the personality of educable mentally retarded children and those of a normal group of children. Exceptional Children 31:457-463, 1965.

27. Schurrer, R., A. WeltmAN, and H. Brammel. Effects of physical training on cardiovascular fitness and behavior patterns of mentally retarded adults. Am. J. Ment. Defic. 90:167-170, 1985.

28. THASE, M. E. Longevity and mortality in Down syndrome. $J$. Ment. Defic. Res. 26:177-192, 1982.

29. Tomporowski, P. and N. ElLIS. Effects of exercise on the physical fitness intelligence and adaptive behavior of institutionalized mentally retarded adults. Appl. Res. Ment. Retard. 5:329-337, 1984. 